\title{
The Brief Technical Analysis on Power System Automation
}

\author{
Tao Liu \\ Jinzhou Power Supply Branch \\ State Grid Liaoning Electric Power Supply Co. Ltd \\ Jinzhou, China \\ liutjz@163.com
}

\author{
Fusheng Zhang \\ Jinzhou Power Supply Branch \\ State Grid Liaoning Electric Power Supply Co. Ltd \\ Jinzhou, China \\ zhangfsjz@163.com
}

\begin{abstract}
With computer technology in power system applications, power system gradually automated upgrade, effectively improve the efficiency of the system operation and improve the efficiency of the power companies. At the same time the realization of the power system automation can make the power system be normal and stable operation in the supply and production process every step. Integration of the power system of scientific management has laid a solid foundation. Power system automation mainly refers to the power transmission and automate the entire process of production management and scheduling through automation equipment with automatic control and automatic detection function.Today, this paper is on the stage of power system automation technology research. The first is a brief introduction to the concept of power system automation and its implementation, Then it analyzes the power system automation technology, and the prospect of future power system automation trends.
\end{abstract}

Keywords- applications; power system; automation; transmission; management

\section{INTRODUCTION}

In recent years, with the development of computer and communication technology, the power system has become into a computer, "Communications" control and power electronics equipment for the integration of systems. Automated information system processing power is growing, increasingly wide range of observations, the object of the closed-loop control of more and more abundant. To ensure the safety of the power system "smooth" healthy run, the various components of the power system "local" whole system, using devices with automatic detection of "decision-making and control functions, signal and data transmission through the system, perform local or remote automatic monitoring "regulation and control, so as to achieve acceptable power quality[1].

Power System and Automation with the development of the electric power industry and automation technology and developed application-oriented basic subjects. The main research interests are power system operation and control theory, artificial intelligence applications in power systems, HVDC technology, power-line monitoring and control system technology, microcomputer relay protection. Professional range of applications, including analysis of power system operation and control, power market analysis, aspects of dispatching automation, relay protection, information management, power management of modern enterprises, factory automation, and intelligent instrument stations in power system applications[2]. Power Automation need to have a solid knowledge of the basic theory of electrical engineering disciplines, to engage in high-level engineering and technical personnel of the power system automation research, design, operation and management in power engineering, electrical engineering automation and other industries.

All aspects of the production process are all areas of power system automation, such as automatic detection, regulation and control, automated security systems and components, automatic transmission and other network information. Its goal is to ensure the supply of power quality (frequency and voltage), the system is safe and reliable operation, enhance economic efficiency and management effectiveness [3]. Establishment of electrical engineering and automation of common network system can optimize the allocation of resources, so that the exchange of information between businesses get the accuracy and security guarantees. A business involves many steps device control, technical supervision, business management, etc., in order to make these steps to get to rationalize the allocation of resources, it is necessary to make these systems linked through the network! Electrical engineering and automation through the establishment of a common network system, so that each data between the systems are efficient, fast switching, prompting optimize the development of the whole enterprise! Only electrical engineering and automation of data can be standardized docking information, electrical engineering and automation systems to transmit information will be more secure, more efficient. Therefore, in the current development of power engineering and automation of the process, we must achieve the perfect docking program interface, thereby reducing the time and cost of development projects.

\section{THE CONCEPT AND APPLICATION OF POWER SYSTEMS AUTOMATION}

Power system is a huge, dynamic network operating systems, including electricity, power supply, power generation three main systems. Its operation has variability, there is a dynamic system modeling in the design of power network operation module. Power 
Systems Division relatively wide area, many of the components exhibit hysteresis, delay, saturation and other complex physical characteristics, so to exercise effective control will be faced with enormous technical difficulty. With the development of society and economy, technology upgrading, the power companies are to market liberalization, which for power enterprises is also very big challenge, we must adopt effective policies and measures to enhance the core competitiveness of enterprises, longterm development of the power system automation. Here, we have the following main aspects discussed in detail in the next stage of China's electric power automation system implementation and development. [4].

\section{A. Power system automation concept}

Power system automation technology refers to the use of various devices with automatic detection and decision control functions through the data transmission system and signal system of each component of the power system, the local system or a system-wide automatic monitoring, coordination and control technology to ensure the security and stability of the power system can be run to ensure reliability of supply. Specifically, it is the computer in the electric power companies in the control center, power system automation of radiation to the surrounding network monitoring system, and by varying power plants and substations fed back information to be monitored for data analysis, and gradually the formation of a comprehensive three-dimensional information transmission, information monitoring and network coverage. Generally speaking, the regulation of the power system by the central computer to be responsible for, and a number of related data records, the preparation, by the information processing system of the individual responsible for monitoring equipment. Throughout the system, through mutual transfer between computers, and combined with each other, including a computer system with a combination of hardware and other equipment, and ultimately automate the process of expansion and control the depth of range[5]. Among them, the automatic operation of the power system is mainly based on a hierarchical approach to control, device control between systems, substations, dispatch stations and power plants to form a hierarchical organization, and delineate the scope of science, depending on the function performed rational, scientific scheduling, monitoring, sharing, and ultimately achieve a reasonable and safe power system reliable and scientific operation.

\section{B. Power system automation to achieve}

Power system automation devices are mostly the same, but with the development of society and economy, device model and type of power system has undergone great changes. In order to effectively ensure the safe and stable operation of the power system, power system equipment must be regulated, especially for a regulation of the equipment must be added each time equipment monitoring and control devices, and protective devices and other communications equipment, which is the power system Automation achieve the most basic conditions. Also, the power companies for the automation of power-line monitoring system provides a very necessary technical support. With the development of our national economy, advances in science and technology, safe and stable operation of the power system more and more people's attention, because the power has been widely applied to the production of human life to go, so the use and continuous improvement of power system automation technology to achieve real-time power system to effectively monitor and manage, not only can improve the reliability of power system operation, can enhance the security of the power system operation. Therefore, the power system automation technology and rational development and application of automation of power system development has great benefits [6].

\section{POWER SYSTEM AUTOMATION AND INTELLIGENT CONTROL SYSTEMS}

\section{A. Automation of Electric Power Systems}

Power system automation mainly refers to the power transmission and automate the entire process of production management and scheduling through automation equipment with automatic control and automatic detection function. Using automated technology enables automated remote and local control of power system "regulating and monitoring power system stability" provides safety "normal operation, and satisfy the actual needs of the power quality. Realize the power of automation to improve the systematic operation of the system level power has a very important practical significance, and its automation including substation automation "distribution automation and distribution automation and scheduling, automation power systems for the power system stability" to provide protection and safe operation, improve power supply system quality, economic efficiency of enterprises realize the power and management efficiency.

From the perspective of substation automation system design point of view, the designer's view of the substation monitoring and control has been achieved from the local to the overall transformation. The current substation automation systems, object-oriented technology has become a very popular trend, one that is not simply the amount of consideration, but with complete protection and monitoring device is a device to perform specific functions, thus ensuring distributed openness of the system. From the trend of technological development, the future and the primary equipment monitoring and control equipment will be fully integrated, that is to achieve a so-called smart devices, each object contain protection, monitoring, accounting, operations, blocking a series of functions and information base, oriented automation is only one pair of twisted pair communication, the twisted pair network mode and connected to a computer [7].

\section{B. Combined with intelligent technology and automation of power systems}

Development of intelligent automation technology for power system development provides a higher platform. In the application of intelligent power system automation technology can not only be able to develop and improve the power of automation technology, but also through the effective application of intelligent systems that can effectively coordinate the instability of the power system! Given the current development of the power system is not 
very mature, so in order to make possible inexpensive and convenient to meet the public demand for electricity network, the application of intelligent technology to which the power system is necessary. However, the current level of China's electric power system automation is not very high, very mature in all aspects of development, there are different degrees of some of the problems and imperfections.

\section{POWER SYSTEM AUTOMATION TECHNOLOGY}

\section{A. Substation Automation}

At present, the development of substation automation has achieved some success, making the substation operation costs have been reduced to a great extent, to enhance the likelihood of scheduling and transmission and distribution grid. On the control strategy to optimize the growing "Adaptation" intelligent "coordination" of regional development. Because of substation automation has run steady state "high degree of automation aspects of the characteristics in the substation at all levels has been widely used! Utilize automation technology, the ability to replace the phone manually operated and manual monitoring, allowing safe operation level and work efficiency is greatly improved [8].

\section{B. Dispatching automation}

Dispatching automation including core computer control system and when "computing software system! Dispatching automation technology during electricity production, the use of the power system security and operational status of analysis and monitoring for real-time analysis, automatic power market scheduling, to meet the electricity needs of the actual market operators in the control means increasing the application of computer "power electronic devices and remote communication. Power plants and substations in the part of information gathering for remote end, scheduling end is mainly used for remote terminal collected information for scheduling.

\section{Substation Integrated Automation}

Substation Integrated Automation by modern electronic technology "information processing technology and the use of computer technology for substation equipment" instrument to optimize the design and feature set, realize the measurement of the main line and associated substation equipment "automatic control and monitoring of overall management. goal to optimize the "coordination" of intelligent development, for example, excitation control "flow control. This technology has the characteristics of commissioning and operation easy maintenance, etc., making the substation protection performance greatly enhanced to achieve a substation remote monitoring and management tools for all.

A control and coordination of integrated automation system. Exchange information between devices through the substation automation systems, data sharing, complete substation monitoring and control tasks. Substation automation replaced conventional substation secondary equipment, simplifying the secondary wiring substation. Substation substation automation is to improve the level of security and stability, lower operation and maintenance costs, improve economic efficiency, provide an important measure of high-quality power to the user.

\section{Distribution Automation}

Distribution automation technology by combining distribution lines and distribution substations, common synthetic distribution network, with a fragmented "points" and other aspects of a wide range of features. The technology for the distribution network for real-time monitoring of running status, and thus distribution network improvement and optimization of operating modes, when the distribution network failure, abnormal operation occurs, distribution automation technology can promptly identify the fault and to be an effective treatment measures.

Distribution automation technology is to serve the urban and rural power grids with the construction of an important technology, distribution automation, including feeder automation and distribution management systems, communication technology is the key distribution automation. At present, China has been more experimental distribution automation, power distribution from the main station, sub-station and a three-layer structure consisting of feeder terminal has been widely recognized as a communication mode optical fiber communication backbone has also been a consensus. Feeder automation implementations are fully able to build on the basis of optical fiber communications, which allows the feeder terminal to quickly communicate with each other to jointly achieve higher performance feeder automation [9].

\section{INTELLIGENT POWER SYSTEM TECHNOLOGY}

\section{A. Fuzzy Control}

Fuzzy control is mainly used in a vague macro control system, which has the characteristics of ease of "nonlinear" randomness "simplistic and uncertainty, these features make the supervision of fuzzy relational model has become very simple and easy, and has very big advantage. superiority of fuzzy control methods are reflected in any place, including household appliances, he makes it very easy to master control operation and very simple. this fuzzy theory of intelligent technology in the power system automation has a very practical value control, because he was able to simulate human decisionmaking process and fuzzy reasoning.

\section{B. Linear optimal control}

Optimal control is an important part of modern control theory, but also a reflection of the optimization theory is used to control the problem. Linear optimal control is currently the most modern control theory and many applications, the most mature of a branch. Lu Qiang, who proposed the use of optimum excitation control means to improve the long-distance transmission lines transmission capacity and improve the dynamic quality problems, made a series of important research results. The study pointed out that in terms of large-scale units should be directly instead of using the optimal excitation control classical excitation mode. Linear optimal controller power system has been widely used in electricity production, plays an important role.

\section{Expert System Control}

Expert systems in the power system a wide range of applications, including the state of the power system in a warning or emergency identification, provide emergency treatment to restore control system is very slow state 
transition analysis, load shedding, system planning, voltage and reactive power control isolation, power distribution system automation, dispatcher training, shortterm load forecasting of power system fault point, static and dynamic security analysis, and advanced humanmachine interface and so on. Although the expert system has been widely used in the power system. But there are still some limitations[10].

\section{Neural Network Control}

Neural network control is evolved by artificial neural network, which is mainly used in learning and model structure, and has been widely disseminated and results. Non-linear neural network control is currently the most attention, in addition to its robust capabilities "processing power and self-learning ability are also subject to people's attention. Neural network is composed of a large number of simple neurons connected together in a certain way the neural network. Depending on specific issues, there have been a variety of neural network structure and training algorithm has been applied in the power system, the main theory of neural network hardware implementation of neural networks have asked topic of research and learning algorithms of neural networks.

\section{CONCLUSION}

Currently, automation is gradually developed from a single cell and the whole system is part of the region, there is a single function gradually developed for the integration of "multi-functional. In the control strategy is increasingly toward the adaptation of" optimization "regionalization and intelligent direction. With the level of scientific and technological advances, intelligent technology has been widely used in various fields, for the purposes of the power system, its significance is particularly important. Although electricity power systems, smart technology has been widely used, when the current trend to look, computer hardware and software-based intelligent technology in the power system will be more comprehensive application. in addition, the intelligent technology and automation technology will be more closely integrated to yield good use of the grid system.

With computer technology, control technology and information technology, automation power system is facing unprecedented change. Multimedia technology "Intelligent Control will soon enter the field of electric power system automation, and the development of information technology, will not only promote the development of the power system monitoring and control of power systems will promote to a higher level of development.

\section{ACKNOWLEDGMENT}

The authors gratefully acknowledge the contribution of co-workers and reviewers' comments.

\section{REFERENCES}

[1] H.B.Tan, "Power system automation control technology down," Techno.Heal.Into.Devel, vol.18,pp.92-95, June 2012

[2] H.F.Yue, "Safety management of wind farms," Scie. Tech.Info, vol. 12,pp.23-27, May 2011

[3] Y.F.Xiao and L.Y.Liu.,"Application of Intelligent Technology in Power System Automation,” Tech. and Enter.,vol.15,pp.17-21, July 2011

[4] Q.Zhang, "Explore the application of intelligent technology in the automation of power systems," Urban.Dev.Theory. vol.11,pp.5960, April 2013

[5] H.L.Xu, "Application of intelligent power system automation technology," Association Forum, vol.2,pp.12-16, June 2012

[6] J.Hao. "Brief Power System and Automation Development Trend," Elect.Pro,vol.4,pp.34-38, May 2013

[7] F.Yang, "Application of Power System Automation million control technology," Value Engineering, vol. 12,pp.13-16, May 2010

[8] J.Liu, "Power system automation control technology," Theor. Urb.Const, vol.19,pp.24-27, May 2011

[9] T.Y.Liang, " Since the eruption of the power system application development trends and new technology," City.Buil.The.Study, vol.13, pp.34-38, April 2011

[10] P.Wang, " Application of Power System Automation trends and new technologies," Coal, vol.9, pp.18-24, April 2012 